\title{
Potential Drug Interactions with Drugs Used for Bipolar Disorder: A Comparison of 6 Drug Interaction Database Programs
}

\author{
Authors \\ Scott Monteith ${ }^{1}$, Tasha Glenn², Michael Gitlin ${ }^{3}$, Michael Bauer ${ }^{4}$
}

Affiliations

1 Michigan State University College of Human Medicine, Traverse City Campus, Traverse City, MI, USA

2 ChronoRecord Association, Fullerton, CA, USA

3 Department of Psychiatry and Biobehavioral Sciences, Semel Institute for Neuroscience and Human Behavior, University of California Los Angeles (UCLA), Los Angeles, CA, USA

4 Department of Psychiatry and Psychotherapy, University Hospital Carl Gustav Carus, Medical Faculty, Technische Universität Dresden, Dresden, Germany

\section{Key words}

drug interaction, bipolar disorder, drug Interaction checkers, drug interaction software

$\begin{array}{ll}\text { received } & 30.12 .2019 \\ \text { revised } & 05.04 .2020 \\ \text { accepted } & 06.04 .2020\end{array}$

Bibliography

Pharmacopsychiatry 2020; 53: 220-227

DOI 10.1055/a-1156-4193

Published online: 1.5 .2020

ISSN 0176-3679

(C) 2020. Thieme. All rights reserved.

Georg Thieme Verlag KG, Rüdigerstraße 14,

70469 Stuttgart, Germany

\section{Correspondence}

Scott Monteith, MD

Michigan State University College of Human Medicine

Traverse City Campus

1400 Medical Campus Drive

Traverse City

MI 49684

USA

monteit2@msu.edu $\bigoplus \begin{aligned} & \text { Supporting Information Appendix } 1 \text { for this article is available } \\ & \text { online at https://doi.org/10.1055/a-1156-4193 }\end{aligned}$

\section{ABSTRACT}

Background Patients with bipolar disorder frequently experience polypharmacy, putting them at risk for clinically significant drug-drug interactions (DDI). Online drug interaction database programs are used to alert physicians, but there are no internationally recognized standards to define DDI. This study compared the category of potential DDI returned by 6 commercial drug interaction database programs for drug interaction pairs involving drugs commonly prescribed for bipolar disorder.

Methods The category of potential DDI provided by 6 drug interaction database programs (3 subscription, 3 open access) was obtained for 125 drug interaction pairs. The pairs involved 103 drugs (38 psychiatric, 65 nonpsychiatric); 88 pairs included a psychiatric and nonpsychiatric drug; 37 pairs included 2 psychiatric drugs. Every pair contained at least 1 mood stabilizer or antidepressant. The category provided by 6 drug interaction database programs was compared using percent agreement and Fleiss kappa statistic of interrater reliability.

Results For the 125 drug pairs, the overall percent agreement among the 6 drug interaction database programs was $60 \%$; the Fleiss kappa agreement was slight. For drug interaction pairs with any category rating of severe (contraindicated), the kappa agreement was moderate. For drug interaction pairs with any category rating of major, the kappa agreement was slight.

Conclusion There is poor agreement among drug interaction database programs for the category of potential DDI involving psychiatric drugs. Drug interaction database programs provide valuable information, but the lack of consistency should be recognized as a limitation. When assistance is needed, physicians should check more than 1 drug interaction database program.

\section{Introduction}

Drug-drug interactions (DDI) contribute to emergency department visits, hospital admissions, longer hospital stays, and increased costs to society [1]. The consequences of most DDI are less severe, often misinterpreted as reduced efficacy, and are an ongoing challenge in psychiatric practice [2,3]. Drug interaction database pro- grams are widely recognized as the primary tool to assist physicians in preventing DDI but also demonstrate the need to understand the limitations of automation [4]. There are no internationally recognized standards to define DDI risk [5,6], and database programs use different methods to search, identify and classify risk [7-9]. 
Factors that increase the risk for DDI include older age, polypharmacy, pharmacological properties of drugs, genetic polymorphisms, multimorbidity, and multiple prescribers at different locations [1014]. Many of these factors are present when treating patients with bipolar disorder. The recurrent, episodic, and heterogeneous nature of bipolar disorder often requires complex treatment regimens for the long-term [15]. Outpatients with bipolar disorder, including the elderly, routinely experience polypharmacy defined as 2 or more psychiatric medications [16-21]. Between $18-36 \%$ of patients with bipolar disorder received 4 or more psychiatric medications $[16,17,21,22]$. The pharmacological properties of many drugs prescribed for bipolar disorder may contribute to serious DDI [23], including lithium [24, 25], some antiepileptics [26, 27], antipsychotics [28, 29], and antidepressants [28]. There is a high burden of comorbid medical illness in patients with bipolar disorder [30,31].

We previously investigated the category of potential DDI for drug interaction pairs containing a psychiatric drug and found that the category returned by drug interaction programs often differed [32]. Due to the increased risk for potential DDI in bipolar disorder, this study compared the category of potential DDI returned by 6 drug interaction database programs for drug interaction pairs containing a mood stabilizer or antidepressant. In this study, the mood stabilizer or antidepressant was paired with another psychiatric drug or a nonpsychiatric drug. The drug interaction pairs were checked using 6 drug interaction database programs, 3 subscription and 3 open access services.

\section{Methods}

\section{Drug interaction database programs and categories}

The 6 drug interaction database programs that were compared included 3 subscription programs: Clinical Pharmacology owned by Elsevier [33], Lexicomp owned by Wolters Kluwer as included in Uptodate [34], and Micromedex owned by IBM [35]. The 3 open access programs included drugs.com owned by the Drugsite Trust [36], Medscape owned by the WebMD Network [37], and Epocrates owned by Athenahealth, Inc [38]. All 6 products are commonly used by clinicians.
After entering a drug interaction pair, each of the 6 drug interaction database programs returns a category for potential DDI, along with explanatory information and evidence in different formats. The categories returned are similar but have different names. For this analysis, the categories were converted into 6 categories: severe (contraindicated), major, moderate, minor, none, and missing. ( Table 1). If a drug interaction database program returned more than 1 category of potential DDI for a drug pair, the most serious category was selected. The searching occurred between 10/10/2019 and 10/20/2019.

\section{Drug interaction pairs}

The 125 drug interaction pairs that were searched involved 103 drugs: 38 psychiatric drugs and 65 nonpsychiatric drugs. Of the 125 drug interaction pairs, 88 pairs included a psychiatric and nonpsychiatric drug, and 37 included 2 psychiatric drugs. All 125 drug interaction pairs contained at least 1 mood stabilizer (lithium, antiepileptic, or antipsychotic) or antidepressant. Drugs routinely prescribed by psychiatrists were considered psychiatric drugs, although some psychiatric drugs have FDA approval for indications outside of psychiatry. The 125 drug interaction pairs that were searched are listed in Appendix 1.

Multiple resources were used to select the 125 drug interaction pairs. These include studies of potential DDI detected in various healthcare settings [11,39-44], reviews of potential DDI involving psychiatric drugs [23, 27, 28, 45-47], lists of serious drug interactions used in prior testing of drug interaction database programs [48-50], and lists of frequently prescribed drugs [51, 52]. All 125 drug interaction pairs had at least 1 category rating of major from at least one of the 6 drug interaction database programs.

\section{Interrater percent agreement and reliability}

Two methods were used to compare agreement in the category provided by the 6 drug interaction database programs: the percent agreement and the Fleiss kappa statistic. For each of the 125 drug interaction pairs, the percent agreement in the category provided by the 6 drug interaction database programs was calculated (the number of ratings that agree divided by the total number of ratings, or 6) [53]. The mean for all 125 drug interaction pairs was then calculated for the overall percent agreement.

- Table 1 Drug interaction categories returned by 6 drug interaction database programs converted to study categories.

\begin{tabular}{|l|l|l|l|l|l|l|}
\hline \multirow{2}{*}{$\begin{array}{l}\text { Study } \\
\text { Category }\end{array}$} & \multicolumn{5}{|c|}{ Database Categories for Each Database } \\
\cline { 2 - 6 } & Clinical pharmacology & Micromedex & Lexicomp & Epocrates & Drugs.com \\
\hline Severe & $\begin{array}{l}\text { Level 1. Severe- } \\
\text { contraindicated; } \\
\text { Severe-avoid }\end{array}$ & Contraindicated & (X) Avoid combination & Contraindicated & Major-contraindicated & Contraindicated \\
\hline Major & Level 2. Major & Major & $\begin{array}{l}\text { (D) Consider therapy } \\
\text { modification }\end{array}$ & Avoid/use alternative & Major & $\begin{array}{l}\text { Serious-use } \\
\text { alternative }\end{array}$ \\
\hline Moderate & Level 3. Moderate & Moderate & (C) Monitor therapy & $\begin{array}{l}\text { Monitor/modify } \\
\text { treatment }\end{array}$ & Moderate & Monitor closely \\
\hline Minor & Level 4. Minor & Minor & (B) No action needed & Caution advised & Minor & Minor \\
\hline None & None & Unknown & $\begin{array}{l}\text { (A) No known } \\
\text { interaction }\end{array}$ & $\begin{array}{l}\text { No significant } \\
\text { interactions found }\end{array}$ & Unknown \\
\hline Missing * & Missing & Missing & Missing & Missing \\
\hline * One drug in pair not in database. & & & Missing \\
\hline
\end{tabular}


The Fleiss kappa statistic was also used to summarize agreement among the 6 drug interaction database programs. A Fleiss kappa statistic was calculated for each category of potential DDI, as well as an overall statistic for all category ratings. The Fleiss kappa statistic measures the agreement between raters that is above the level expected by chance, and is suitable for 3 or more raters [54]. A Fleiss kappa value varies from - 1.0 (perfect disagreement) to 0 (agreement expected by chance) to 1.0 (perfect agreement). The scale of Landis and Koch was used to interpret the strength of agreement of the Fleiss kappa value. A kappa value of $<0.00$ is poor agreement, $0.00-0.20$ is slight agreement, $0.21-0.40$ is fair agreement, $0.41-0.60$ is moderate agreement, $0.61-0.80$ is substantial agreement and $0.81-1.00$ is almost perfect agreement [55]. P-values are calculated for the Fleiss kappa, with statistical significance $(p<0.05)$ meaning that rater agreement was not due solely to chance. Although Fleiss kappa is a measure of agreement among raters, high agreement does not always mean the answer is correct, and low agreement does not always mean the answer is incorrect. The R software package "irr" Version 0.84.1 was used for all Fleiss kappa statistic calculations [56].

\section{Results}

The overall percent agreement in category provided by the 6 drug interaction programs for the 125 drug interaction pairs was $60 \%$. There was no difference in percent agreement between drug interaction pairs including a psychiatric and nonpsychiatric drug (60\%) and pairs with 2 psychiatric drugs (59\%). For the 125 drug interaction pairs, the range in category results returned (least to most severe category) is shown in > Fig. 1. The drug interaction pairs with the broadest range of categories from the 6 drug interaction programs are shown in $>$ Tables 2 and $>\mathbf{3}$. \ Table 2 shows the drug interaction pairs with at least 1 rating of severe and a range that differed by 2 or more categories (none-severe, minor-severe, moderate-severe). $>$ Table 3 shows the drug interaction pairs with at least 1 rating of major and a range that differed by 2 or more categories (none-major, minor-major, missing-major).
For the 125 drug interaction pairs, the overall Fleiss kappa statistic was 0.142 (slight agreement) as shown in > Table 4. The Fleiss kappa statistic for drug interaction pairs with any category rating of severe was 0.426 (moderate agreement) and 0.068 (slight agreement) for pairs with any category rating of major.

Disagreement in the category of potential DDI occurred even for well-documented DDI, such as between selective serotonin reuptake inhibitors (SSRI) and monoamine oxidase inhibitors (MAOI) [57]. There was $83 \%$ agreement for citalopram + selegiline (5 severe, 1 major), $67 \%$ agreement for sertraline + rasagiline (2 severe, 4 major), and $100 \%$ agreement for escitalopram + tranylcypromine (6 severe).

Drug interaction database programs are updated periodically. Of the 125 drug interaction pairs, 33 were used in our previous analysis in 2018 [32]. For these 33 drug interaction pairs, a total of $21(11 \%)$ category changes across the 6 drug interaction database programs were found. Of the 21 changes, 8 (38\%) ratings increased in severity and 13 (62\%) decreased in severity.

The web sites for all 6 drug interaction database programs include detailed disclaimers and terms of use statements, which stipulate that the information provided is intended only to supplement and assist the physician and not as a replacement for professional knowledge and judgement. All 6 companies provide information on an "as is" basis and assume no responsibility or liability.

\section{Discussion}

The category of potential DDI returned by the 6 drug interaction programs for the 125 drug interaction pairs, all with at least 1 rating of major, often did not agree. The overall interrater reliability was slight, and only moderate for potential DDI in the severe (contraindicated) category. Poor agreement between drug interaction database programs is well documented [58-60], including in studies of psychiatric and antiepileptic drugs that involve potential DDI rated major or severe [32,61-64]. Potential DDI are challenging to define and detect $[5-7,14]$, and both polypharmacy and biologics further increase the methodological complexity [65-67]. Experts

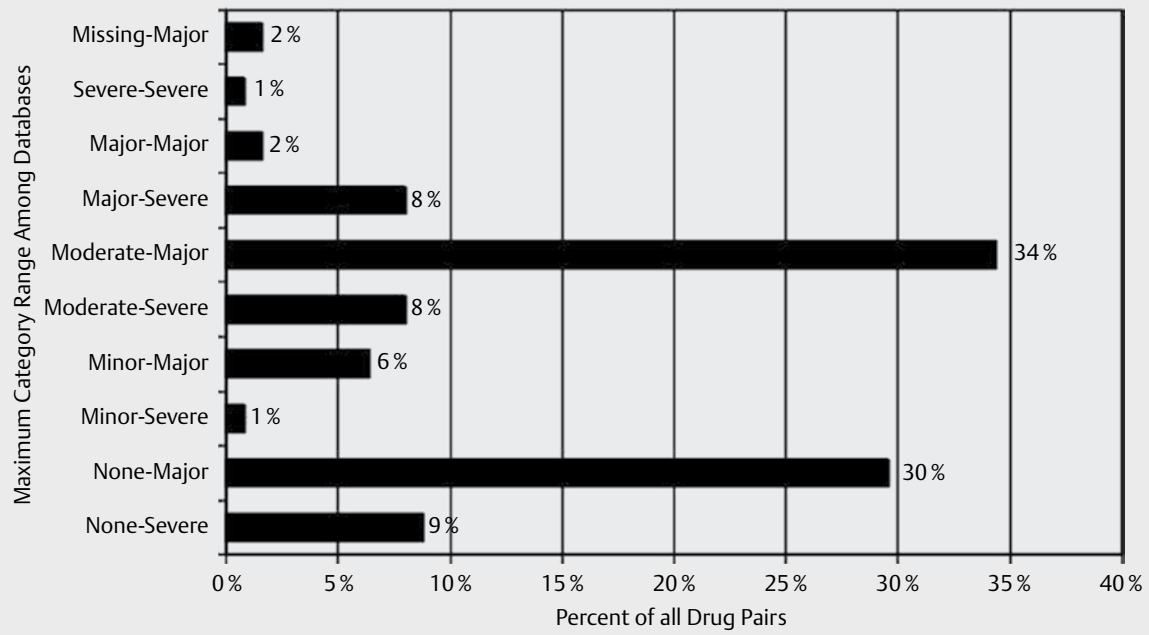

Fig. 1 Maximum category range of potential DDI from the 6 drug interaction database programs for the 125 drug interaction pairs. 
- Table 2 Drug interaction pairs with at least one severe rating and a range that differed by 2 or more categories.

\begin{tabular}{|c|c|c|c|}
\hline & Drug Pair & \% Agreement & All Database Categories \\
\hline \multicolumn{4}{|l|}{ None to Severe Range } \\
\hline & amitriptyline + potassium chloride & $50 \%$ & 3 severe, 3 none \\
\hline & citalopram + metoclopramide & $33 \%$ & 1 severe, 2 major, 1 moderate, 1 minor, 1 none \\
\hline & divalproex + lesinurad & $33 \%$ & 1 severe, 1 major, 2 moderate, 2 none \\
\hline & haloperidol + potassium chloride & $67 \%$ & 2 severe, 4 none \\
\hline & olanzapine + alprazolam & $50 \%$ & 1 severe, 3 moderate, 1 minor, 1 none \\
\hline & olanzapine + potassium chloride & $50 \%$ & 3 severe, 3 none \\
\hline & quetiapine + revefenacin & $50 \%$ & 1 severe, 1 major, 1 moderate, 3 none \\
\hline & sertraline + disulfiram & $50 \%$ & 2 severe, 1 major, 3 none \\
\hline & venlafaxine + quinidine & $33 \%$ & 1 severe, 2 major, 1 minor, 2 none \\
\hline & ziprasidone + atomoxetine & $50 \%$ & 1 severe, 1 major, 1 moderate, 3 none \\
\hline & ziprasidone + tamoxifen & $50 \%$ & 2 severe, 1 major, 3 none \\
\hline \multicolumn{4}{|l|}{ Minor to Severe Range } \\
\hline & ziprasidone + amitriptyline & $33 \%$ & 2 severe, 2 major, 1 moderate, 1 minor \\
\hline \multicolumn{4}{|l|}{ Moderate to Severe Range } \\
\hline & aripiprazole + ketoconazole & $50 \%$ & 1 severe, 3 major, 2 moderate \\
\hline & citalopram + amiodarone & $67 \%$ & 1 severe, 4 major, 1 moderate \\
\hline & citalopram + dofetilide & $67 \%$ & 1 severe, 4 major, 1 moderate \\
\hline & escitalopram + fluconazole & $67 \%$ & 1 severe, 1 major, 4 moderate \\
\hline & lurasidone + atazanavir & $67 \%$ & 1 severe, 4 major, 1 moderate \\
\hline & olanzapine + lorazepam & $50 \%$ & 1 severe, 3 major, 2 moderate \\
\hline & quetiapine + ziprasidone & $50 \%$ & 3 severe, 2 major, 1 moderate \\
\hline & quetiapine + dronedarone & $67 \%$ & 4 severe, 1 major, 1 moderate \\
\hline & quetiapine + sotalol & $67 \%$ & 1 severe, 4 major, 1 moderate \\
\hline & ziprasidone + hydroxyzine & $50 \%$ & 2 severe, 3 major, 1 moderate \\
\hline
\end{tabular}

disagree on search strategies, resources for seeking evidence, and processes to rank evidence and classify potential DDI [7, 9]. Drug interaction database programs use various information sources and have inconsistent criteria to define severity $[5-9,59,68]$. These inconsistencies in evidence and classification criteria may lead to large discrepancies in the category of potential DDI returned $[63,68]$, as found in the current study. Until there are standardized measures to evaluate and classify evidence, clinicians should expect different products to provide different results. It is important that clinicians recognize this limitation of drug interaction database programs and, as noted in prior research, consult more than 1 source as needed $[32,63,69]$.

When treating patients taking polypharmacy for years, such as those with bipolar disorder, the risk of clinically significant DDI is recurrent. The physician must interpret the potential DDI category from a drug interaction database program for the individual patient, despite many challenges. Information in the EMR is often incorrect. For example, the medication list in the EMR is often inaccurate $[70,71]$, with at least 1 medication discrepancy found for $85 \%$ of 438 patients at a psychiatric clinic [72]. Both clinical and mental health data, including diagnoses, may be missing from the EMR [73-75] such that both psychiatrists and general doctors are prescribing with an incomplete understanding of the patient history.

Many challenges are related to polypharmacy. Patients taking polypharmacy usually have a unique drug regimen, resulting in more possible drug interaction pairs than ever could be studied clinically [67]. In a study of 353 patients with a stable treatment regimen for bipolar disorder, 231 patients took a unique medication regimen when considering only the psychiatric drugs [16]. A larger number of psychiatric drugs was associated with irregularity in the daily dosage taken of mood stabilizers and antidepressants in patients with bipolar disorder [76,77]. Since many patients with bipolar disorder are partially adherent or nonadherent, drug concentrations in the blood may not be at therapeutic levels [78]. In a study of 115 highly selected, adherent patients from a psychiatric clinic, who took at least 5 psychiatric and nonpsychiatric drugs, the concentration of $41 \%$ of drugs was below and $6 \%$ above the specific blood reference range for each drug, and $13 \%$ of detected drugs were not in the EMR [79].

DDI involving 2 psychiatric drugs may be difficult to detect and be misinterpreted as toxicity or reduced efficacy $[2,80]$. For example, an added drug may gradually increase the serum concentration and unwanted side effects of an ongoing drug, with the DDI misinterpreted as an adverse reaction. Alternatively, an added drug may decrease the serum concentration of an ongoing drug, so the patient appears treatment resistant. Off-label prescribing is associated with adverse events [81], and many psychiatric drugs are prescribed off-label in psychiatry and primary care [82, 83].

Other challenges relate to the implementation of drug interaction database programs. Changes to the prescribing workflow may be cumbersome $[84,85]$. Alert fatigue remains a major issue as the majority of DDI alerts are overridden [86, 87]. Physicians often feel that most DDI alerts do not require action or are clinically insignificant, or that the risk for an individual patient is lower than shown 
- Table 3 Drug interaction pairs with at least one major rating and a range that differed by 2 or more categories

\begin{tabular}{|c|c|c|c|}
\hline & Drug Pair & \% Agreement & All Database Categories \\
\hline \multicolumn{4}{|l|}{ None to Major Range } \\
\hline & aripiprazole + escitalopram & $50 \%$ & 1 major, 3 moderate, 1 minor, 1 none \\
\hline & aripiprazole + topiramate & $67 \%$ & 1 major, 4 moderate, 1 none \\
\hline & asenapine + dofetilide & $67 \%$ & 4 major, 1 moderate, 1 none \\
\hline & asenapine + zonisamide & $33 \%$ & 1 major, 2 moderate, 1 minor, 2 none \\
\hline & carbamazepine + atorvastatin & $50 \%$ & 2 major, 3 moderate, 1 none \\
\hline & carbamazepine + dexamethasone & $50 \%$ & 2 major, 3 moderate, 1 none \\
\hline & carbamazepine + diazepam & $50 \%$ & 2 major, 3 moderate, 1 none \\
\hline & cariprazine + bupropion & $33 \%$ & 2 major, 2 moderate, 2 none \\
\hline & cariprazine + topiramate & $33 \%$ & 2 major, 1 moderate, 1 minor, 2 none \\
\hline & citalopram + atomoxetine & $33 \%$ & 1 major, 2 moderate, 1 minor, 2 none \\
\hline & citalopram + efavirenz & $67 \%$ & 4 major, 1 moderate, 1 none \\
\hline & citalopram + fingolimod & $50 \%$ & 3 major, 1 moderate, 2 none \\
\hline & clozapine + cyclophosphamide & $33 \%$ & 2 major, 2 moderate, 2 none \\
\hline & clozapine + adalimumab & $83 \%$ & 1 major, 5 none \\
\hline & clozapine + lenalidomide & $33 \%$ & 2 major, 2 moderate, 2 none \\
\hline & divalproex + topiramate & $67 \%$ & 1 major, 4 moderate, 1 none \\
\hline & escitalopram + enoxaparin & $50 \%$ & 3 major, 2 moderate, 1 none \\
\hline & escitalopram + pimavanserin & $50 \%$ & 3 major, 1 minor, 2 none \\
\hline & escitalopram + valbenazine & $67 \%$ & 1 major, 1 minor, 4 none \\
\hline & haloperidol + valbenazine & $67 \%$ & 1 major, 1 moderate, 4 none \\
\hline & lamotrigine + buprenorphine & $50 \%$ & 2 major, 1 moderate, 3 none \\
\hline & lithium + amiodarone & $50 \%$ & 2 major, 1 moderate, 3 none \\
\hline & lithium + quetiapine & $50 \%$ & 1 major, 3 moderate, 2 none \\
\hline & lithium + sumatriptan & $33 \%$ & 2 major, 2 moderate, 1 minor, 1 none \\
\hline & olanzapine + donepezil & $50 \%$ & 1 major, 3 moderate, 2 none \\
\hline & olanzapine + escitalopram & $50 \%$ & 1 major, 3 moderate, 1 minor, 1 none \\
\hline & perphenazine + bupropion & $50 \%$ & 3 major, 2 moderate, 1 none \\
\hline & quetiapine + fluvoxamine & $50 \%$ & 1 major, 3 moderate, 1 minor, 1 none \\
\hline & quetiapine + zolpidem & $50 \%$ & 1 major, 3 moderate, 2 none \\
\hline & risperidone + ondansetron & $50 \%$ & 3 major, 2 moderate, 1 none \\
\hline & sertraline + clarithromycin & $50 \%$ & 3 major, 1 moderate, 1 minor, 1 none \\
\hline & venlafaxine + bupropion & $50 \%$ & 3 major, 1 moderate, 2 none \\
\hline & venlafaxine + vemurafenib & $50 \%$ & 3 major, 3 none \\
\hline & ziprasidone + furosemide & $50 \%$ & 1 major, 3 moderate, 2 none \\
\hline & ziprasidone + pramipexole & $50 \%$ & 3 major, 2 moderate, 1 none \\
\hline & ziprasidone + zonisamide & $33 \%$ & 1 major, 2 moderate, 1 minor, 2 none \\
\hline & ziprasidone + hydrochlorothiazide & $50 \%$ & 1 major, 3 moderate, 2 none \\
\hline \multicolumn{4}{|l|}{ Minor to Major Range } \\
\hline & citalopram + aspirin & $67 \%$ & 1 major, 4 moderate, 1 minor \\
\hline & fluoxetine + donepezil & $50 \%$ & 1 major, 2 moderate, 3 minor \\
\hline & lithium + sertraline & $50 \%$ & 3 major, 2 moderate, 1 minor \\
\hline & olanzapine + ciprofloxacin & $67 \%$ & 1 major, 4 moderate, 1 minor \\
\hline & quetiapine + ciprofloxacin & $50 \%$ & 2 major, 3 moderate, 1 minor \\
\hline & quetiapine + escitalopram & $50 \%$ & 3 major, 2 moderate, 1 minor \\
\hline & sertraline + aspirin & $67 \%$ & 1 major, 4 moderate, 1 minor \\
\hline & sertraline + warfarin & $50 \%$ & 2 major, 3 moderate, 1 minor \\
\hline \multicolumn{4}{|l|}{ Missing to Major Range } \\
\hline & cariprazine + boceprevir & $50 \%$ & 3 major, 1 none, 2 missing \\
\hline & cariprazine + iohexol & $33 \%$ & 2 major, 2 none, 2 missing \\
\hline
\end{tabular}


- Table 4 Fleiss kappa interrater agreement among the 6 drug interaction database programs for 125 drug interaction pairs.

\begin{tabular}{|l|l|c|l|}
\hline Category & Kappa & P-value & Strength of Agreement ${ }^{*}$ \\
\hline Severe & 0.426 & $<0.001$ & Moderate \\
\hline Major & 0.068 & 0.003 & Slight \\
\hline Minor & 0.015 & 0.511 & Slight \\
\hline None & 0.188 & $<0.001$ & Slight \\
\hline Missing & 0.196 & $<0.001$ & Slight \\
\hline Overall & 0.142 & $<0.001$ & Slight \\
\hline${ }^{*}$ Landis and Koch 1977. \\
\hline
\end{tabular}

$[87,88]$. Some physicians feel the DDI information provided by the drug interaction database program is incorrect, including half of 118 psychiatrists surveyed [89]. For example, in this study the category of potential DDI for 3 drug pairs containing an SSRI and MAOI was rated major, rather than severe, in 5 of 18 ratings (27.8\%). Alert override may become a habitual behavior, such that an alert acts as a cue that automatically triggers an override response [90]. Automation bias may also occur, with some prescribers becoming over-reliant on the drug interaction database program to detect potential DDI at the exclusion of clinical judgement [91].

Drug interaction database programs provide a large amount of information and are an important and helpful tool. Physicians see patients by specialty and may only have a limited knowledge of DDI $[92,93]$. Realistically, it is not possible for a physician to accurately identify all potentially serious DDI. In 2019, the FDA Orange Book of all drugs approved as safe and effective has 3959 entries [94], while the FDA Purple Book of biologics and biosimilars has 29 entries [95]. Additionally, classification of potential DDI is an ongoing process, as shown by the category change in $11 \%$ of the drug interaction pairs investigated a year ago [32]. However, the lack of consistency in results from drug interaction programs in this study and many prior studies should be recognized as a limitation of this technology. If the physician requires assistance in determining potential DDI, more than 1 database product should be checked. Given that most physicians have continual Internet access, physicians can easily obtain multiple independent opinions from more than 1 product. If questions remain after the use of another product, a human expert should be consulted. Routine use of drug interaction database programs underscores the importance of clinical judgement and expertise. The prescriber must recognize when to ask for assistance from a human expert.

There are limitations to this analysis. The results could change after drug interaction database programs are updated and if different drug interaction pairs were searched. There was no attempt to assess or compare the accuracy of the category of potential DDI or to investigate the methodology used to define DDI risk. Other features of the drug interaction database programs including ease of use, quality of information display, integration with the EMR, and impacts on physician workflow were not evaluated. Supplements are commonly used by patients with bipolar disorder [96], but drug interactions with supplements, alcohol, food, smoking, and illegal drugs were not considered. Legal issues related to DDI [97] and the use of psychiatric drugs purchased online from rogue pharmacies were not discussed $[98,99]$.
Physicians should understand the limitations as well as the capabilities of technology products that impact medical decision making. Ultimately, physician judgement will determine if there is a potential DDI for the individual patient, often requiring a nuanced interpretation of many complex factors. All physicians recognize that drugs have limitations including adverse reactions and DDI. Likewise, physicians should recognize that technology has limitations, and an important limitation of drug interaction database programs is the lack of consistency. When a physician needs assistance from a drug interaction database program, more than 1 program should be checked.

\section{Conflict of interest}

The authors declare that they have no conflict of interest.

\section{References}

[1] FDA. Preventable adverse drug reactions: a focus on drug interactions. 2018. Accessed at: https://www.fda.gov/drugs/drug-interactions-labeling/ preventable-adverse-drug-reactions-focus-drug-interactions\#ADRs:\%20 Prevalence\%20and\%20Incidence; Accessed: Dec. 5, 2019

[2] Gören JL, Tewksbury A. Drug interactions and polypharmacy. In: Ritsner MS, Ed. Polypharmacy in Psychiatry Practice, Volume I. Multiple Medication Use Strategies. Dordrecht: Springer; 2013: 45-74

[3] Magro L, Moretti U, Leone R. Epidemiology and characteristics of adverse drug reactions caused by drug-drug interactions. Expert Opin Drug Saf 2012; 11: 83-94

[4] Bauer M, Monteith S, Geddes J et al. Automation to optimise physician treatment of individual patients: examples in psychiatry. Lancet Psychiatry 2019; 6: 338-349

[5] Scheife RT, Hines LE, Boyce RD et al. Consensus recommendations for systematic evaluation of drug-drug interaction evidence for clinical decision support. Drug Saf 2015; 38: 197-206

[6] Tilson H, Hines LE, McEvoy G et al. Recommendations for selecting drug-drug interactions for clinical decision support. Am J Health Syst Pharm 2016; 73: 576-585

[7] Grizzle AJ, Horn J, Collins C et al. Identifying common methods used by drug interaction experts for finding evidence about potential drug-drug interactions: Web-based survey. J Med Internet Res 2019; 21: e11182

[8] Kongsholm GG, Nielsen AK, Damkier P. Drug interaction databases in medical literature: Transparency of ownership, funding, classification algorithms, level of documentation, and staff qualifications. A systematic review. Eur J Clin Pharmacol 2015; 71: 1397-1402

[9] Romagnoli KM, Nelson SD, Hines L et al. Information needs for making clinical recommendations about potential drug-drug interactions: A synthesis of literature review and interviews. BMC Med Inform Decis Mak 2017; 17: 21

[10] Bourgeois FT, Shannon MW, Valim C et al. Adverse drug events in the outpatient setting: An 11-year national analysis. Pharmacoepidemiol Drug Saf 2010; 19: 901-910

[11] English BA, Dortch M, Ereshefsky L et al. Clinically significant psychotropic drug-drug interactions in the primary care setting. Curr Psychiatry Rep 2012; 14: 376-390

[12] Guthrie B, Makubate B, Hernandez-Santiago $V$ et al. The rising tide of polypharmacy and drug-drug interactions: population database analysis 1995-2010. BMC Med 2015; 13: 74 
[13] Ong MS, Olson KL, Chadwick L et al. The impact of provider networks on the co-prescriptions of interacting drugs: a claims-based analysis. Drug Saf 2017; 40: 263-272

[14] Tannenbaum C, Sheehan NL. Understanding and preventing drug-drug and drug-gene interactions. Expert Rev Clin Pharmacol 2014; 7: 533-544

[15] Bauer M, Andreassen OA, Geddes JR et al. Areas of uncertainties and unmet needs in bipolar disorders: clinical and research perspectives. Lancet Psychiatry 2018; 5: 930-939

[16] Bauer M, Glenn T, Alda M et al. Drug treatment patterns in bipolar disorder: analysis of long-term self-reported data. Int J Bipolar Disord 2013; 1: 5

[17] Golden JC, Goethe JW, Woolley SB. Complex psychotropic polypharmacy in bipolar disorder across varying mood polarities: A prospective cohort study of 2712 inpatients. J Affect Disord 2017; 221: 6-10

[18] Greil W, Häberle A, Haueis P et al. Pharmacotherapeutic trends in 2231 psychiatric inpatients with bipolar depression from the International AMSP Project between 1994 and 2009. J Affect Disord 2012; 136: 534-542

[19] Peselow ED, Naghdechi L, Pizano D et al. Polypharmacy in maintenance of bipolar disorder. Clin Neuropharmacol 2016; 39: 132-134

[20] Rej S, Herrmann N, Shulman K et al. Current psychotropic medication prescribing patterns in late-life bipolar disorder. Int J Geriatr Psychiatry 2017; 32: 1459-1465

[21] Weinstock LM, Gaudiano BA, Epstein-Lubow G et al. Medication burden in bipolar disorder: a chart review of patients at psychiatric hospital admission. Psychiatry Res 2014; 216: 24-30

[22] Goldberg JF, Brooks JO 3rd, Kurita K et al. Depressive illness burden associated with complex polypharmacy in patients with bipolar disorder: findings from the STEP-BD. J Clin Psychiatry 2009; 70: 155-162

[23] de Leon J, Spina E. Possible pharmacodynamic and pharmacokinetic drug-drug interactions that are likely to be clinically relevant and/or frequent in bipolar disorder. Curr Psychiatry Rep 2018; 20: 17

[24] Finley PR. Drug interactions with lithium: an update. Clin Pharmacokinet 2016; 55: 925-941

[25] Tondo L, Alda M, Bauer M et al. Clinical use of lithium salts: Guide for users and prescribers. Int J Bipolar Disord 2019; 7: 16

[26] Johannessen Landmark C, Patsalos PN. Drug interactions involving the new second- and third-generation antiepileptic drugs. Expert Rev Neurother 2010; 10: 119-140

[27] Spina E, Pisani F, de Leon J. Clinically significant pharmacokinetic drug interactions of antiepileptic drugs with new antidepressants and new antipsychotics. Pharmacol Res 2016; 106: 72-86

[28] Spina E, Trifirò G, Caraci F. Clinically significant drug interactions with newer antidepressants. CNS Drugs 2012; 26: 39-67

[29] Wijesinghe R. A review of pharmacokinetic and pharmacodynamic interactions with antipsychotics. Ment Health Clin 2016; 6: 21-27

[30] Kemp DE, Sylvia LG, Calabrese JR et al. General medical burden in bipolar disorder: findings from the LiTMUS comparative effectiveness trial. Acta Psychiatr Scand 2014; 129: 24-34

[31] Weber NS, Fisher JA, Cowan DN et al. Psychiatric and general medical conditions comorbid with bipolar disorder in the National Hospital Discharge Survey. Psychiatr Serv 2011; 62: 1152-1158

[32] Monteith S, Glenn T. A comparison of potential psychiatric drug interactions from six drug interaction database programs. Psychiatry Res 2019; 275: 366-372

[33] Clinical Pharmacology Drug Interaction. 2019; https://www. clinicalkey.com/pharmacology; Accessed: Dec. 5, 2019

[34] Lexicomp. 2019; https://www.wolterskluwercdi.com/lexicomponline/user-guide/tools-interactions; Accessed: Dec. 5, 2019

[35] IBM Micromedex Medication Management. 2019; https://www.ibm. com/products/micromedex-with-watson; Accessed: Dec. 5, 2019
[36] Drugs.com. Drug Interactions Checker. 2019; https://www.drugs. com/drug_interactions.html; Accessed: Dec. 5, 2019

[37] Medscape 2019; https://reference.medscape.com/drug-interactionchecker; Accessed: Dec. 5, 2019

[38] Epocrates. 2019; https://online.epocrates.com/interaction-check; Accessed: Dec. 5, 2019

[39] Barrett M, Keating A, Lynch D et al. Clozapine patients at the interface between primary and secondary care. Pharmacy (Basel) 2018; 6: 19

[40] Hefner G, Unterecker S, Ben-Omar N et al. Prevalence and type of potential pharmacokinetic drug-drug interactions in old aged psychiatric patients. Contemp Behav Health Care 2015; 1: 3-10

[41] Holm J, Eiermann B, Eliasson E et al. A limited number of prescribed drugs account for the great majority of drug-drug interactions. Eur J Clin Pharmacol 2014; 70: 1375-1383

[42] Jazbar J, Locatelli I, Horvat $\mathrm{N}$ et al. Clinically relevant potential drug-drug interactions among outpatients: A nationwide database study. Res Social Adm Pharm 2018; 14: 572-580

[43] Soerensen AL, Nielsen LP, Poulsen BK et al. Potentially inappropriate prescriptions in patients admitted to a psychiatric hospital. Nord J Psychiatry 2016; 70: 365-373

[44] Zorina OI, Haueis P, Greil W et al. Comparative performance of two drug interaction screening programmes analysing a cross-sectional prescription dataset of 84625 psychiatric inpatients. Drug Saf 2013; 36: 247-258

[45] Kinsella KJ. Drug-drug interactions and psychiatric medication. In: Grossberg GT, Kinsella LJ, (Eds.) Clinical Psychopharmacology for Neurologists. Switzerland: Springer; 2018: 181-200

[46] Smolders EJ, de Kanter CT, de Knegt RJ et al. Drug-drug interactions between direct-acting antivirals and psychoactive medications. Clin Pharmacokinet 2016; 55: 1471-1494

[47] Yap KY, Tay WL, Chui WK et al. Clinically relevant drug interactions between anticancer drugs and psychotropic agents. Eur J Cancer Care (Engl) 2011; 20: 6-32

[48] Kheshti R, Aalipour M, Namazi S. A comparison of five common drug-drug interaction software programs regarding accuracy and comprehensiveness. J Res Pharm Pract 2016; 5: 257-263

[49] McEvoy DS, Sittig DF, Hickman TT et al. 2017. Variation in high-priority drug-drug interaction alerts across institutions and electronic health records. J Am Med Inform Assoc 2017; 24: 331-338

[50] Patel RI, Beckett RD. Evaluation of resources for analyzing drug interactions. J Med Libr Assoc 2016; 104: 290-295

[51] Clincalc.com. The Top 300 of 2019. 2019; https://clincalc.com/ DrugStats/Top300Drugs.aspx; Accessed: Dec. 5, 2019

[52] Urquhart L. Top drugs and companies by sales in 2018. Nature Reviews Drug Discovery 2019; 18: 245

[53] McHugh ML. Interrater reliability: the kappa statistic. Biochem Med (Zagreb) 2012; 22: 276-282

[54] Fleiss JL. Measuring nominal scale agreement among many raters. Psychol Bull 1971; 76: 378

[55] Landis JR, Koch GG. The measurement of observer agreement for categorical data. Biometrics 1977; 33: 159-174

[56] Gamer M, Fellows J, Lemon I et al. 2019. Package “irr.” Various coefficients of interrater reliability and agreement. https:// cran.r-project.org/web/packages/irr/irr.pdf; Accessed: Dec. 5, 2019

[57] Flockhart DA. Dietary restrictions and drug interactions with monoamine oxidase inhibitors: An update. J Clin Psychiatry 2012; 73: Suppl 1 17-24

[58] Abarca J, Colon LR, Wang VS et al. Evaluation of the performance of drug-drug interaction screening software in community and hospital pharmacies. J Manag Care Pharm 2006; 12: 383-389

[59] Vitry A. Comparative assessment of four drug interaction compendia. $\mathrm{Br}$ J Clin Pharmacol 2007; 63: 709-714 
[60] Wang LM, Wong M, Lightwood JM et al. Black box warning contraindicated comedications: Concordance among three major drug interaction screening programs. Ann Pharmacother 2010; 44: 28-34

[61] Acton EK, Willis AW, Gelfand MA et al. Poor concordance among drug compendia for proposed interactions between enzyme-inducing antiepileptic drugs and direct oral anticoagulants. Pharmacoepidemiol Drug Saf 2019; 28: 1534-1538

[62] Ekstein D, Tirosh M, Eyal Y et al. 2015; Drug interactions involving antiepileptic drugs: assessment of the consistency among three drug compendia and FDA-approved labels. Epilepsy Behav 2015; 44: 218-224

[63] Liu X, Hatton RC, Zhu Y et al. Consistency of psychotropic drug-drug interactions listed in drug monographs. J Am Pharm Assoc 2017; 57: 698-703

[64] Schjøtt ], Schjøtt P, Assmus J. Analysis of consensus among drug interaction databases with regard to combinations of psychotropics. Basic Clin Pharmacol Toxicol 2020; 126: 126-132

[65] Bykov K, Gagne J]. Generating evidence of clinical outcomes of drug-drug interactions. Drug Saf 2017; 40: 101-103

[66] Schrieber S], Pfuma-Fletcher E, Wang X et al. Considerations for biologic product drug-drug interactions: A regulatory perspective. Clin Pharmacol Ther 2019; 105: 1332-1334

[67] Sutherland J], Daly TM, Liu X et al. Co-prescription trends in a large cohort of subjects predict substantial drug-drug interactions. PLoS One 2015; 10: e0118991

[68] Roblek T, Vaupotic T, Mrhar A et al. Drug-drug interaction software in clinical practice: A systematic review. Eur J Clin Pharmacol 2015; 71: 131-142

[69] Boyce RD, Collins C, Clayton M et al. Inhibitory metabolic drug interactions with newer psychotropic drugs: inclusion in package inserts and influences of concurrence in drug interaction screening software. Ann Pharmacother 2012; 46: 1287-1298

[70] Coletti DJ, Stephanou H, Mazzola N et al. Patterns and predictors of medication discrepancies in primary care. J Eval Clin Pract 2015; 21: 831-839

[71] Linsky A, Simon SR. Medication discrepancies in integrated electronic health records. BMJ Qual Saf 2013; 22: 103-109

[72] Albano ME, Bostwick JR, Ward KM et al. Discrepancies identified through a telephone-based, student-led initiative for medication reconciliation in ambulatory psychiatry. J Pharm Pract 2018; 31: 304-311

[73] Dornquast C, Tomzik J, Reinhold T et al. To what extent are psychiatrists aware of the comorbid somatic illnesses of their patients with serious mental illnesses? - a cross-sectional secondary data analysis. BMC Health Serv Res 2017; 17: 162

[74] Madden JM, Lakoma MD, Rusinak D et al. Missing clinical and behavioral health data in a large electronic health record (EHR) system. J Am Med Inform Assoc 2016; 23: 1143-1149

[75] O'Neill B, Kalia S, Aliarzadeh B et al. Agreement between primary care and hospital diagnosis of schizophrenia and bipolar disorder: A cross-sectional, observational study using record linkage. PLoS One 2019; 14: e0210214

[76] Bauer R, Glenn T, Alda M et al. Antidepressant dosage taken by patients with bipolar disorder: factors associated with irregularity. Int J Bipolar Disord 2013; 1: 26

[77] Pilhatsch M, Glenn T, Rasgon N et al. Regularity of self-reported daily dosage of mood stabilizers and antipsychotics in patients with bipolar disorder. Int J Bipolar Disord 2018; 6: 10

[78] Bauer M, Glenn T, Alda M et al. Trajectories of adherence to mood stabilizers in patients with bipolar disorder. Int J Bipolar Disord 2019; 7: 19

[79] Sutherland J], Daly TM, Jacobs K et al. Medication exposure in highly adherent psychiatry patients. ACS Chem Neurosci 2018; 9: 555-562
[80] Ereshefsky L. Drug-drug interactions with the use of psychotropic medications. Interview by Diane M. Sloan. CNS Spectr 2009; 14 (8 Suppl Q and A Forum): 1-8

[81] Eguale T, Buckeridge DL, Verma A et al. Association of off-label drug use and adverse drug events in an adult population. JAMA Intern Med 2016; 176: 55-63

[82] Vijay A, Becker JE, Ross JS. Patterns and predictors of off-label prescription of psychiatric drugs. PLoS One 2018; 13: e0198363

[83] Wong J, Motulsky A, Abrahamowicz M et al. Off-label indications for antidepressants in primary care: Descriptive study of prescriptions from an indication based electronic prescribing system. BMJ 2017; 356: j603

[84] Hayward J, Thomson F, Milne $\mathrm{H}$ et al. Too much, too late: Mixed methods multi-chanel video recording study of computerized decision support systems and GP prescribing. J. Am Med Inform Assoc 2013; 20: e76-e84

[85] Slight SP, Eguale T, Amato MG et al. The vulnerabilities of computerized physician order entry systems: A qualitative study. J Am Med Inform Assoc 2016; 23: 311-316

[86] Bryant AD, Fletcher GS, Payne TH. Drug interaction alert override rates in the Meaningful Use era: no evidence of progress. Appl. Clin. Inform 2014; 5: 802-813

[87] Kuperman G], Bobb A, Payne TH et al. Medication-related clinical decision support in computerized provider order entry systems: a review. J Am Med Inform Assoc 2007; 14: 29-40

[88] Armahizer M], Kane-Gill SL, Smithburger PL. Comparing drug-drug interaction severity ratings between bedside clinicians and proprietary databases. ISRN Critical Care. 2013; Article ID 347346. http://dx.doi.org/10.5402/2013/347346; Accessed: Dec. 5, 2019

[89] Phillips KA, Citrome L. Inaccurate prescribing warnings in electronic medical record systems: results from an American Society of Clinical Psychopharmacology membership survey. J. Clin. Psychiatry 2018; 80: 18 ac12536

[90] Baysari MT, Tariq A, Day RO et al. Alert override as a habitual behavior a new perspective on a persistent problem. J Am Med Inform Assoc 2017; 24: 409-412

[91] Lyell D, Magrabi F, Raban MZ et al. Automation bias in electronic prescribing. BMC Med Inform Decis Mak 2017; 17: 28

[92] Glassman PA, Simon B, Belperio P et al. Improving recognition of drug interactions: Benefits and barriers to using automated drug alerts. Med Care 2002; 40: 1161-1171

[93] Ko Y, Malone DC, Skrepnek GH et al. Prescribers' knowledge of and sources of information for potential drug-drug interactions: A postal survey of US prescribers. Drug Saf 2008; 31: 525-536

[94] FDA. Approved Drug Products with Therapeutic Equivalence Evaluations (Orange Book). 2019; https://www.fda.gov/drugs/ drug-approvals-and-databases/approved-drug-products-therapeuticequivalence-evaluations-orange-book; Accessed: Dec. 5, 2019

[95] FDA. Purple Book: Lists of Licensed Biological Products with Reference Product Exclusivity and Biosimilarity or Interchangeability Evaluations. 2019; https://www.fda.gov/drugs/therapeutic-biologicsapplications-bla/purple-book-lists-licensed-biological-products-reference-product-exclusivity-and-biosimilarity-or; Accessed: Dec. 5, 2019

[96] Bauer M, Glenn T, Conell J et al. Common use of dietary supplements for bipolar disorder: A naturalistic, self-reported study. Int J Bipolar Disord 2015; 3: 29

[97] Ridgely MS, Greenberg MD, Too many alerts, too much liability. St. Louis University Journal of Health Law \& Policy 2012; 5: 257-296

[98] Monteith S, Glenn T. Searching online to buy commonly prescribed psychiatric drugs. Psychiatry Res 2018; 260: 248-254

[99] Monteith S, Glenn T, Bauer R et al. Availability of prescription drugs for bipolar disorder at online pharmacies. J Affect Disord 2016; 193: 59-65 